\title{
CARACTERIZAÇÃO DAS LESÕES DE Gallus gallus PROVOCADAS EM RINHAS NO ESTADO DA PARAÍBA, BRASIL
}

\author{
Cynthia Germoglio Farias de MELO ${ }^{1}$; Marcos Antônio Jerônimo COSTA²; Felipe Eduardo \\ da Silva SOBRAL ${ }^{3}$
}

\footnotetext{
${ }^{1}$ Doutora em Produtos Naturais e Sintéticos Bioativos/Universidade Federal da Paraíba (UFPB), Brasil. E-mail: cynthia_fariasm@hotmail.com

${ }^{2}$ Doutor em Ciências Biológicas (Zoologia)/UFPB, Brasil. E-mail: marcoscostajp@gmail.com

${ }^{3}$ Mestre em Sistema Agrossilvipastoril no Semiárido (Zootecnia)/Universidade Federal de Campina Grande (UFCG), Brasil; Professor do curso de Medicina Veterinária/Centro Universitário Maurício de Nassau (UNINASSAU/PB), Brasil. E-mail: felipe_eduardo_med_vet@hotmail.com
}

No Estado da Paraíba tem-se observado com frequência um grande número de animais utilizados para práticas julgadas esportistas como rinhas. Apesar do grande número de lesões observadas nos animais vítimas destes maus tratos, poucos trabalhos são observados relatando estas ocorrências mais detalhadamente. Com objetivo de avaliar os traumas sofridos pelas aves da espécie Gallus gallus, vítima de maus tratos em rinhas, foram analisados 23 espécimes aprendidas pela polícia florestal no município de Santa Rita - PB, e atendidos pelo CETAS (Centro de Triagem de Animais Silvestres). Dos vinte e três indivíduos de G. gallus apreendidos, 100\% apresentaram ausência de penas no alto da cabeça (testa, vértice e nuca) e coxa, 78,2\% exibiam lesões oculares com pelo menos um dos olhos cegos, $39 \%$ necrose auricular, 82,6\% necrose da crista, 39\% perfurações nas regiões peitoral e escapular, 34,7\% perfurações na testa e 17,3\% apresentavam fratura de mandíbula. A principal causa das lesões observadas ocorre devido o uso de instrumentos de metal como biqueiras e esporas colocados no animal para provocar maior dano no adversário. Foi verificado ainda que algumas das lesões observadas provocam nos animais dificuldades de alimentação, comportamento de corte e vocalização.

Palavras-chave: Ave combatente; Ave de briga; Galos. 